Metal-Catalyzed

Asymmetric

Synthesis and

Stereoselective

Reactions

\title{
Synthesis of Substituted Enol Ethers and Their Synthetic Application
}

\section{Key words}

enol derivatives

methylalumination

$$
\mathrm{R}=\frac{\mathrm{Me}_{3} \mathrm{Al} \text {, cat. } \mathrm{Cp}_{2} \mathrm{ZrCl}_{2}}{\substack{\text { cat. } \mathrm{H}_{2} \mathrm{O} \text { or } \mathrm{MAO} \\ \mathrm{CH}_{2} \mathrm{Cl}_{2}}}
$$

Selected examples:

$$
\mathrm{AlMe}_{2} \frac{\begin{array}{c}
\text { EXZ } \\
0^{\circ} \mathrm{C}, 2 \mathrm{~h} \\
E X=\text { electrophile }
\end{array}}{\mathrm{Me}}
$$<smiles>O=C(Cc1ccccc1)OCc1ccccc1</smiles>

$89 \%$<smiles>C/C=C\C=C(\CBr)[N+](=O)[O-]</smiles>

$82 \%$<smiles>CC(=O)OC=C(C=[W])COCc1ccccc1</smiles>

$97 \%$

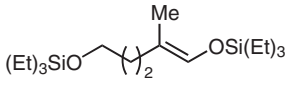

$83 \%$

Asymmetric dihydroxylation (AD) of enol benzoates:

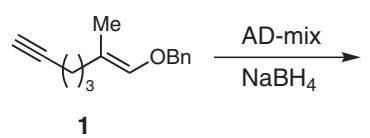

1<smiles>C#C[C@H](O)[C@@](C)(O)CO</smiles>

\section{AD-mix}

$95 \%$ ee from 1 $32 \%$ ee from 2

Transformations of $\alpha$-hydroxy aldehydes:

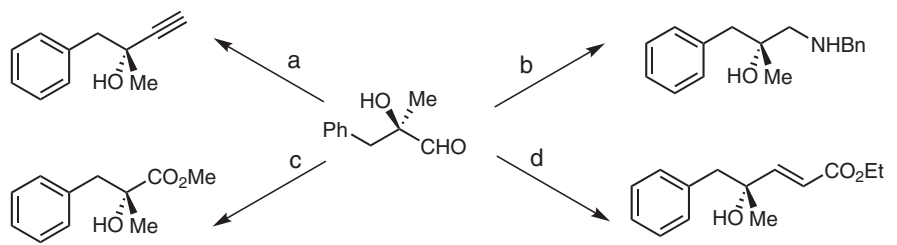

Reagents and conditions: (a) (MeO) ${ }_{2} \mathrm{POCN}_{2} \mathrm{COMe}, \mathrm{K}_{2} \mathrm{CO}_{3}, \mathrm{MeOH}, 0{ }^{\circ} \mathrm{C}$ to r.t.; (b) $\mathrm{BnNH}_{2}$, toluene, $4 \AA \mathrm{MS}, 105^{\circ} \mathrm{C}$; (c) $\mathrm{I}_{2}, \mathrm{KOH}, \mathrm{MeOH}, 0^{\circ} \mathrm{C}$; (d) $\mathrm{Bu}_{3} \mathrm{PCH}_{2} \mathrm{CO}_{2} \mathrm{EtBr}, \mathrm{NaHCO}_{3}$, toluene, $90^{\circ} \mathrm{C}$.

Significance: The authors describe the preparation for trisubstituted enol derivatives via tandem carbometalation-oxygenation of terminal alkynes. The enol derivatives were isolated as a single regioisomer with a high $E$-selectivity $(E / Z>20: 1)$. Stereodefined enol ethers can undergo asymmetric dihydroxylation to yield optically active $\alpha$-hydroxy aldehydes. Finally, $\alpha$-hydroxy aldehydes were shown to undergo homologation to a terminal alkyne, reductive amination, oxidation and olefination.
Comment: Recently, the Ready group reported carbocupration-oxygenation of terminal alkynes as an alternative method for trisubstituted enol derivatives (Org. Lett. 2005, 7, 5681). However, methyl-substituted products were not accessible by this method because of inefficient methyl-cupration of alkynes. In this paper, they described a general method for obtaining methyl-substituted enol ether and explored the asymmetric transformations of stereodefined enol derivatives.

Although it is a simple idea, it works nicely. This method will have broad utility in the future. 